\title{
ASSESSING PRIOR LEARNING IN ENGLISH BUSINESS COMMUNICATION AT A SOUTH AFRICAN UNIVERSITY OF TECHNOLOGY
}

\author{
S. Rossouw* \\ e-mail: rossouws@tut.ac.za \\ C. C. Mann* \\ e-mail: MannC@tut.ac.za
}

\section{L. van Huyssteen*}

e-mail: vanHuyssteenL@tut.ac.za

\section{L. van Ryneveld}

Faculty of Veterinary Science

University of Pretoria

Pretoria, South Africa

e-mail: linda.vanryneveld@up.ac.za

*Department of Applied Languages

Tshwane University of Technology

Pretoria, South Africa

\section{ABSTRACT}

A case study on Recognition of Prior Learning (RPL) was undertaken at a University of Technology (UoT) in South Africa, to determine whether the assessment methods used for the subject, 'English Business Communication', adhered to the principles and ethos of RPL. Focusing on 24 RPL applicants since 2010, the study used document analysis (written exams, questionnaire, oral interviews, portfolios of evidence), a focus group interview with previous applicants, and semistructured interviews with three RPL assessors. The major findings indicated that: the applicants were not in favour of writing an exam paper, and would not like to be tested on theory; they preferred a combination of portfolio of evidence and oral interview. It is recommended that: RPL applicants be given some pre-application orientation; the RPL process timeframe be shortened; in-process feedback on applications be given to applicants; and, a toolkit be compiled to assist and orient applicants and assessors in future.

Key words: Recognition of Prior Learning, RPL policy, RPL principles, RPL assessment methods, RPL process, University of Technology 


\section{INTRODUCTION}

Recognition of prior learning (RPL), which goes by many names, including: Assessment of Prior Learning (APL); Assessment of Prior Experiential Learning (APEL); Prior Learning Assessment and Recognition (PLAR); and, Prior Learning Assessment and Articulation (PLAA) (http://www.plaio.org), is in the field of adult pedagogy. The RPL field is relatively young, in terms of its application, and research.

It began as a 'concept and related set of methodologies in universities in the United States (US)' in the 1970s (Harris 1997, 2). Since 1974, the Council for Adult and Experiential Learning (CAEL) in the USA has created standards to award credits through assessment (http://www.cael.org/pla.htm). From there, the concept of RPL spread to other countries worldwide. South Africa was no exception, though it only happened two decades after the conception in the USA.

To fully understand the concept of prior learning, one needs to understand what learning is. Learning goes hand-in-hand with knowledge. As initially described by Gibbons et al. (1994), Harris (2000, 17-20) distinguishes between Mode 1 knowledge ('knowledge produced by academics and scientists working within discreet disciplines in the academy and research-based institutions'), and Mode 2 knowledge ('socially constructed by multiple actors in specific and multiple local contexts').

Armsby (2013, 413) argues that one learns through experience, and, consequently, didactic processes can incorporate this into their design. RPL fits this bill, as a learning approach.

Billett (2010, 402) affirms that learning is continually happening in the lives of people, and, therefore, he believes that 'everyone is a lifelong learner'. Lifelong learning is used as a concept in education, the work environment, as well as in the community, but, according to Kirby, Knapper, Lamon, and Egnatoff (2010, 291), and Aspin and Chapman (2000, 2), the meaning is often vague and imprecise.

Does a person learn through experience? Is it a given that experience equates to knowledge?

Van Kleef $(2007,5)$ believes that experience is essential to learning, referring to Dewey (1916), an American theorist, who contended that experience is a principal source of learning. He did not separate experience from education, but saw experience as vital to education. The role of education, for him, was to help learners understand and grow from their experiences. Kolb (1984, in Moore and Van Rooyen 2002) asserts that 'People do learn from their experience, and the results of that learning can be reliably assessed and certified for university 
credit'.

Knowles $(1970,44)$ explored the field of adult learning (andragogy), and observed that people acquire a vast amount of experience, as they grow and develop. This experience then becomes a source of learning for them. He believed that adults derive their self-identity from their experiences (Knowles 1970, 50). Adult learning is central to the concept of RPL, and remains in the notion of lifelong learning. Knowles, himself, believed in the importance of adults’ life experiences as worthy of recognition $(1970,497)$.

Cretchley and Castle $(2010,491,497)$ share Knowles' view that adult learners are 'mature, experienced, and motivated people who are competent to take responsibility for their own learning'.

RPL initiatives are often related to mobility, in one sense or another, according to Andersson and Fejes (2010, 202). They observe that recognition of prior learning is associated with the procedure of transfer or mobility of knowledge, and maintain that:

[P]eople need to get recognition for what they have learnt before, often in another context, to be able to use their knowledge - in terms of its use value and/or its exchange value - in the new context. It could be a matter of mobility between countries, between workplaces, or from informal to formal learning contexts, i.e., from daily/working life to education $(2010,203)$.

Frick (2007) is of the opinion that, besides formal adult learning, non-formal and informal learning has amplified in South Africa. She ascribes this to different requirements and desires of the populace, and suggests that lifelong learning is propelled forward 'by the global economy as well as the need for social and political pressures for equity and redress' $(2007,58)$.

However, academics evinced some resistance toward RPL in higher education, when first introduced, since RPL made traditional boundaries between these two modes of knowledge more permeable (knowledge displayed by RPL candidates would be seen as Mode 2 knowledge, devoid of 'academic speak', and RPL candidates, on the other hand, would struggle, if confronted with Mode 1 knowledge in academia).

Michelson (2012) remarks that, since university is seen as the terrain where knowledge is produced, RPL challenges this notion, as knowledge obtained by RPL candidates outside the academic environment in the workplace, community, and the like, now vies for credit awards the same as for traditional students. By obtaining these credits, RPL candidates are placed in the same position as regular students, who followed the traditional academic route.

Hendricks and Volbrecht $(2003,52)$ surmise that, in their experience, academics had 'greater resistance to RPL for advanced standing than for access to undergraduate studies'. It may be because the universities would not like to lose potential subsidies - their main source 
of income (Van Rooy 2002, 80).

In a study done in Australia in 2009, it was found that more than 75 per cent of their public universities granted some form of RPL (Pitman and Vidovich 2013, 502). Their policies are epistemological in nature, as they want to ensure that prior learning is assessed as 'equivalent in content and level to the course for which RPL is being sought' (Pitman and Vidovich 2013, $502)$.

This indicates that universities, or institutions of higher education, are buying into RPL, whether out of their own accord, or in reaction to national policies. RPL should not be seen as an easy alternative (or 'soft option') to obtain credits. The integrity of the course and the university must remain stable.

RPL evolves by a number of basic principles, without which it would not have any credibility or currency: validity (of knowledge and skills assessment, so as to promote 'equality and inclusion in education and training, creating a more flexible labour market') (Diederich 2013, 548); reliability (consistency of assessment) (Sweygers et al. 2009, 99); authenticity (evidence of ownership of the knowledge and skills); fairness (using set criteria and learning outcomes, with mutual understanding between assessor and assessee) (Sandberg and Andersson 2011, 778); sufficiency (of skills, experience, and knowledge assessed against learning outcomes); appropriateness (of assessment methods, if they are fit-for-purpose); quality assurance (use of proper procedures, following laid-down policy: at least two assessors and assessments; one moderator); and, transparency (openness and integrity of the process).

As suggested earlier, the ethos of RPL is to allow for access and mobility to (higher) formal educational and/or professional qualifications through an assessment of knowledge, skills, and/or experience previously or currently acquired usually at the workplace. Given the socio-historical and socio-economic past of the disadvantaged (Black) majority of South Africans during the oppressive, apartheid era, RPL is a welcome, practical mechanism of redress, correction, and societal transformation, especially in higher education.

\section{RPL IN THE SOUTH AFRICAN CONTEXT}

Given that RPL in the South African context was developed post-1990, mainly to redress the inequalities engendered by the education system during the apartheid era, it is understandable that it had a political and ideological orientation. RPL originated through the initiatives of trade unionists and workplace trainers associated with the various National Training Boards, replaced by Sector Education and Training Authorities (SETAs) in 1998 (Breier, in Harris, Breier, and Wihak 2011). 
Although Breier suggests that, in developing the national policy, South Africa borrowed ideas from England, Scotland, Australia, and New Zealand, there were factors to consider that were unique to the South African environment (Harris et al. 2011). One of these challenges she mentions is the fact that South Africa is a developing country, and given the educational background (or lack thereof) of many South Africans, it stands to reason that the basic literacy and numeracy levels of the average South African would not be at par with those of citizens of the developed countries; hence, different approaches were necessary.

Ralphs (2012, 75) observes that RPL was established in South Africa's education and training system as part of a three-way discourse; namely, to rectify past inequities; recognise lifelong learning; and, improve 'flexibility and articulation capabilities' within the National Qualifications Framework (NQF).

The reason for developing an RPL policy for the South African context was two-fold, according to Beekman (2001, 18); namely, 'educational correction for recognition of all learning', but also adherence 'to the ideological principles of justice and equity to redress past inequalities where all the people in South Africa did not have the means or opportunities to obtain a formal education'.

While RPL's foundation in South Africa may lie in political and educational redress, Ralphs $(2012,76)$ points out that the implementation of the RPL policy had been 'a lot more costly, contested and complex than was anticipated by policy makers'. He refers to the renowned, international researchers on RPL, Michelson and Harris, who had warned that RPL could not effortlessly be divorced from 'conservative conventions that are set up to monitor compliance with national standards and registered qualifications' (Ralph 2012, 76). This is one of the reasons that research in South Africa is on-going, as the South African context lends itself to it.

Osman (2004) also observed that RPL in South Africa differs from the international view on RPL. Internationally, RPL is the vehicle to address, and enhance, 'individual empowerment, growth and self-esteem' $(2004,139)$. On the other hand, South Africa is, policy-wise, driven by the need for access to previously educationally-disadvantaged people, and the redress of past inequalities.

Breier (in Harris et al. 2011) indicates that RPL formally commenced when the South African Qualifications Authority (SAQA) officially declared that 'all qualifications may be achieved in whole or in part through RPL'. However, in the higher education sector, the 50 per cent residency clause implemented at universities prohibits the achievement of a whole qualification through RPL. The 50 per cent residency clause was developed to enable students 
at a higher education institution to transfer credits from one institution of higher education to another (Heyns 2004, 17). Be that as it may, higher education institutions are also bound by the laws promulgated by the authorities.

After its inception, a ministerial task team set up to assess its evolution observed a number of challenges, but stressed the interest in 'its capacity to engage with cultures of knowledge and learning that characterise the struggle for survival and transformation in many marginalised communities' (DHET 2013, 10). They underlined that 'The role of RPL, in providing alternative routes of access to further and higher education and training programmes, is vital in the promotion and delivery of a national "returning to learning” strategy for unemployed and under-qualified youth and adults. It is pivotal to building a learning nation.' $(2013,11)$.

In sum, RPL in higher education is not a new concept, but it only came to the fore in South Africa in the early 1990s, after the end of apartheid. At that stage, and still today, institutions of higher learning have traditional methods of assessment, of which a written examination is the most common used. With the coming of RPL to the doorsteps of universities, lecturers, as subject specialists, are expected to conduct these assessments. Both RPL for access, and RPL for advanced standing, are practised at universities. In South Africa, higher education institutions are allowed to formulate their own institutional policies, although they are governed by the National Policy on RPL.

\section{THE STUDY}

A study, ${ }^{1}$ related to RPL for advanced standing, was undertaken in the Department of Applied Languages at a university of technology in Pretoria. The Department has been involved in Recognition of Prior Learning (RPL) assessment since 2004. There was no formal university policy, at that stage, but the guidelines of the South African Qualifications Authority (SAQA) were followed in the assessment of RPL applicants. The subject, 'English Business Communication', is a generic subject at the UoT, and taught to students across seven Faculties. Although the core syllabus is generic, the application thereof is tailored to the needs of the client departments.

The study set out to determine: i) whether the assessments adhered to basic principles of RPL; ii) whether the assessment methods then used for 'English Business Communication' were appropriate for RPL; iii) obstacles experienced by applicants in the RPL process; and, iv) whether the processes and procedures followed were efficient for RPL. The applicants' knowledge and skills, not their experience in their respective career fields, needed to be assessed against the learning outcomes of the subject, to determine whether the applicants met these 
criteria, and had the necessary language skills to express themselves.

The first step was to look at policy, practice, and the criteria of RPL internationally, to get an idea of where South Africa was positioned globally. The RPL policies of some of the universities nationally, as well as the policy of this UoT, were explored, in order to get a sense of this University's position in the South African academic environment. The RPL practices and processes of the UoT under review were studied, as well as how RPL was implemented in this environment. In addition, the RPL assessments employed in the subject, 'English Business Communication', were evaluated, to ascertain whether these methods were compatible with RPL principles.

The benefits of RPL seem to be apparent: in terms of RPL for access, both the applicant and the institution benefit. RPL applicants have an opportunity to access the higher education sector, obtain a qualification, which may afford them the chance to gain better employment, thereby resulting in their socio-economic uplift. The economy would also benefit, by absorbing more skilled people into the work force. The universities benefit as well, as they would produce graduates, and obtain subsidies, in turn. With regard to RPL for advanced standing, RPL applicants would be able to fast-track their qualifications, even though they cannot RPL a whole qualification, on account of the 50 per cent residency clause binding on universities.

Where there are benefits, there are sure to be challenges as well. Firstly, being institutions of higher learning, it stands to reason that university lecturers, being subject specialists, would have to facilitate RPL assessments in their respective departments. This places an additional burden on them, in addition to lecturing, and other departmental responsibilities, as well as research that they need to conduct. The cost of the RPL application is an issue for both the applicant and the university. While the applicant would not have to pay the full subject fee, it may still serve as a barrier to prevent people from applying, if they do not have the means to do so. In this way, it would also prevent people who were disadvantaged in the previous disposition (i.e., under apartheid) to apply for RPL, in order to obtain qualifications. It has an implication for the university as well, as they need class fees, to be financially sustainable. It could be a reason why universities cap the number of RPL applications per year. Language proficiency could constitute another obstruction. Most universities in South Africa have English as the language of instruction; therefore, RPL assessments would be in the language of instruction. If an applicant is not proficient in English, it might have an impact on their performance.

RPL, as a part of education, opens up many possibilities for applicants to gain access to higher education, or to fast-track their qualifications. Furthermore, RPL, as a research field, lies wide open, waiting to be explored. 


\section{Research methodology and participants' profiles}

The research paradigm chosen was interpretive in nature, to address the appropriateness of the current RPL assessment methods, using the insights and opinions of the participants. These opinions were contextualised and interpreted, using mainly a qualitative research approach, although a quantitative research instrument (questionnaire) was also used to support and confirm the qualitative data.

Using both qualitative and quantitative methods gave the study a pragmatic base. This was accomplished by using crystallisation to look at the issues from different perspectives. The research strategy chosen was a case study, as it was adopted to gain an in-depth understanding of a phenomenon, or problem. Ellingson (2009) explains that crystallisation is a multi-genre qualitative approach, which can incorporate quantitative research instruments, and combine multiple forms of analysis, to have a richer and deeper understanding of the problem.

Using purposive sampling, the target population and sample was limited to the RPL applicants since 2010 at the specific Department of Applied Languages at a specific UoT in South Africa ( $\mathrm{N}=24)$. These applicants were administrative and secretarial staff members of the University. Three experienced RPL Assessors in the Department of Applied Languages were interviewed on their views on the adherence to principles of RPL, appropriateness of the assessment methods, and the RPL processes and procedures. (see Table 1, for the participants' profiles.)

Table 1: Profiles of RPL Applicants and Assessors ( $N=27)$

\begin{tabular}{|c|c|c|c|}
\hline \multicolumn{2}{|l|}{ Variables } & \multirow{2}{*}{$\begin{array}{c}\text { RPL Applicants }(\mathbf{n = 2 4 )} \\
12\end{array}$} & \multirow{2}{*}{$\frac{\text { RPL Assessors }(n=3)}{-}$} \\
\hline Race & Black & & \\
\hline & Coloured & 1 & - \\
\hline & White & 11 & 3 \\
\hline \multirow[t]{2}{*}{ Gender } & Female & 16 & 2 \\
\hline & Male & 8 & 1 \\
\hline \multirow{4}{*}{$\begin{array}{l}\text { Age range } \\
\text { (in years) }\end{array}$} & $20-29$ & 1 & - \\
\hline & $30-39$ & 10 & - \\
\hline & $40-49$ & 13 & 2 \\
\hline & $60-70$ & - & 1 \\
\hline \multirow[t]{5}{*}{ Home Language* } & Afrikaans & 11 & 3 \\
\hline & sePedi & 4 & - \\
\hline & isiNdebele & 3 & - \\
\hline & seTswana & 2 & - \\
\hline & isizulu & 2 & - \\
\hline \multirow[t]{2}{*}{ Highest Qualification } & Matric & 18 & - \\
\hline & Certificate & 2 & - \\
\hline
\end{tabular}




\begin{tabular}{|l|l|c|c|}
\hline \multicolumn{2}{|l|}{ Variables } & RPL Applicants (n=24) & RPL Assessors (n=3) \\
\hline \multirow{4}{*}{} & National Diploma & 4 & - \\
\cline { 2 - 4 } & BA (Hons.) & - & 1 \\
\cline { 2 - 4 } & MTech. & - & 1 \\
\cline { 2 - 4 } & PhD & - & - \\
\hline \multirow{2}{*}{$\begin{array}{l}\text { Work Experience (in) } \\
\text { years) }\end{array}$} & $0-5$ & 2 & 1 \\
\cline { 2 - 4 } & $6-10$ & 8 & - \\
\cline { 2 - 4 } & $11-20$ & 6 & 2 \\
\cline { 2 - 4 } & $20+$ & 8 & \\
\hline
\end{tabular}

*Only main home language frequencies presented

Document analysis of assessment methods was used (written exams, oral interviews, and portfolios of evidence [PoEs]), and a focus group interview with previous RPL applicants, semistructured interviews with three RPL assessors in the specific Language Department were conducted. A questionnaire was also designed to include more participants (than those whose portfolios could still be retrieved). This questionnaire served to support the qualitative data, in terms of themes extracted. (See Table 2, for the RPL applicants' statuses at the time of applying for RPL, and their reasons for applying.)

Table 2: Statuses of RPL Applicants and Reasons for Applying* $(n=24)$

\begin{tabular}{|l|c|}
\hline Status at time of RPL application & RPL Applicants \\
\hline University staff member appointed on condition of improving qualifications & 11 \\
\hline University staff member appointed with no condition & 10 \\
\hline University registered student & 2 \\
\hline (Did not answer): & 1 \\
\hline Reasons for RPL Application* & 16 \\
\hline I have enough work experience & 7 \\
\hline Keeping my job depended on getting my qualification & 7 \\
\hline I believed I knew enough about the subject & 3 \\
\hline I did not want to waste time studying through normal channels & 3 \\
\hline It was the shortest route to obtaining my qualification & 3 \\
\hline I did not want to attend evening classes & 4 \\
\hline (Other): & \\
\hline
\end{tabular}

${ }^{*}$ Respondents could tick as many boxes as were applicable to them

The written exams usually comprised of the following tasks (marks allocated indicated): a mind map and presentation of text (30); meetings notice and agenda (20); employment (section of CV; answering interview questions; letter of resignation - 30); conflict resolution (10); reading comprehension (20); memo writing (20); and, editing (10). The total marks awarded were 140.

The oral interview was usually conducted between the applicant and two assessors. Five questions were asked, based on the learning outcomes of the subject. The applicants had to show that they understood, and could answer, questions comprehensively, and cite practical 
examples from their work environments, to link the learning outcomes to the knowledge and skills acquired at work. Some examples of interview questions posed related to possible barriers to effective communication at the workplace; distinguishing between verbal and non-verbal forms of communication (with examples at the workplace); how to resolve conflict situations (using scenarios); human relations; and, personnel management.

The focus group interview fielded the following questions: What were your expectations, prior to the assessment? How fair do you think the two assessments were, in terms of testing your knowledge and skills acquired in industry? How did you feel about the written assessment? How did you prepare for the Portfolio of Evidence? What do you consider to be the advantages and disadvantages of a Portfolio of Evidence as an assessment method for subject RPL? What were your experiences with the oral assessment? What obstacles did you encounter during the RPL process? How do you think you should have been assessed for 'English Business Communication'?

For the PoEs, assessors developed a rubric of assessment, based on the learning outcomes of the subject RPL. The applicants were required to compile a portfolio of documents that they prepared themselves in their work environments. They were given the following criteria: i) Communication Theory, Principles, and Techniques (organisational communication, with examples of documents compiled; reading and writing skills - ability to reflect on learning that took place, placing learning outcomes in context; visual/graphical communication, with examples of own work; ii) Language Acts of the Individual (intensified persuasion, with examples of persuasive messages; interviewing, consulting, and negotiating skills; problemsolving, with examples); iii) Language Acts in Business and Industry (group communication; employment application, e.g., letter of application, CV; advanced practice in: correspondence, with examples of work emails, memoranda, letters, other documents; report-writing - an example of a report written; meeting procedures, with examples of agendas, minutes). The assessment binary descriptor was 'competent'/'not competent'.

Data analysis was conducted through a process of coding. These codes were then grouped into categories and themes identified. The themes were used to address the research questions. Ethical issues were addressed by assuring the participants that their anonymity would be protected, and that the data obtained would be handled confidentially. As per the institution's policy, the Research Ethics Committee gave permission for the data collection methods to be used.

\section{Findings}


The main findings presented by content analysis were sub-divided into: written exams, oral interviews, and portfolios of evidence, as these were the assessment methods used since 2010. The PoEs were given as an option of assessment in 2010. Thereafter, the assessors opted for the written exam, and the oral interview, in order to be more time-efficient, and to speed up an already lengthy process.

\section{Assessments}

The majority of assessments were conducted using the written exam as assessment tool. The main findings from perusing the written exam scripts were that the applicants managed to express themselves fairly well. They could interpret the questions correctly, though there were a number of learning outcomes that they did not perform well in.

The RPL applicants struggled mainly with writing a text for a presentation. Article writing and presentation skills are part of the learning outcomes of 'English Business Communication'. For both, the applicants should know how to write the text. It was found that the RPL applicants struggled with this learning outcome, which may suggest that it is not a task they have to perform during their daily activities at work. Nevertheless, the applicants should have been able to, at least, write a comprehensive text, as the scenario given to them (as background to the presentation) was something that they should have been able to write about. They lacked knowledge of the basic structures of a written text; namely, introduction, body, and conclusion.

Another learning outcome that was not answered very well was Business Correspondence, which includes writing of letters and short forms of communication, e.g., memoranda and emails. The RPL applicants showed a tendency to lack detail when writing.

Conflict resolution was another learning outcome not answered comprehensively by the applicants. They did not supply sufficient detail in their descriptions of a conflict situation. This should not have been difficult for them, as they should have experienced conflict situations in their work environments. Resolving the conflict should not have been difficult either, but this question was not answered very well.

The area where the applicants fared best in was meeting procedures. All of these applicants would have been familiar with meeting procedures, as it forms part of all types of business environments.

The applicants were not in favour of writing an exam paper, and the major findings indicated that they were anxious, as they had not written an exam for a long time. They also thought they should not be tested on theory, like regular students, though this 'theory' formed part of the learning outcomes of the subject. These emotions (anxiety and stress) experienced 
by the applicants might be attributed to the fact that the written exam is a traditional assessment method; thus, academic in nature, and these applicants felt uncomfortable doing an assessment of this kind after so many years of being absent from an academic environment. The applicants' profiles indicate that the majority had Matric (Grade 12) as their highest qualification; thus, they had no experience of higher education, nor of the assessments administered therein.

Most of the applicants fared better in the oral interview assessment; they expressed themselves with ease, even if their performances were rated as 'average' (51 per cent). This could be attributed to the fact that they used English as the language of communication at work. South Africa may have eleven official languages, but the main business language is English. Some applicants appeared nervous, at the start of the interviews - which could be attributed to the fact that they were questioned on the learning outcomes of the subject; in addition, they did not know what to expect at the oral interview.

The Portfolio of Evidence (PoE) is one of the assessment methods employed to assess prior learning. Although this is an assessment method preferred by many assessors and RPL applicants alike, it remains a difficult tool to use. It proved difficult for the applicants to prepare a PoE, in spite of the guidelines and criteria given.

In the portfolio, the applicants needed to include documents compiled by them at work, as well as demonstrate that they could match these to the learning outcomes of the subject. They also needed to reflect on the learning acquired at work. Compiling a portfolio is not an easy thing to do; a lot of thought has to go into the preparation, and it could take a long time to complete. Applicants need to be given sufficient time to compile the portfolio. This, in turn, adds to the already lengthy RPL process. Regarding the authenticity of portfolios, the time aspect of compiling a portfolio has implications for the applicant, as well as the assessor. The applicant needs to spend time compiling the portfolio, amidst work pressure, and the same goes for the assessors, who have to spend time in instructing the applicants on how to compile a portfolio, and then assessing it. RPL assessments per se are already an added load for academics.

In terms of the assessment methods used currently for 'English Business Communication', the applicants made it clear that they preferred the PoE and oral interview, as assessment methods. They felt that this was the best way to test their prior learning, as they could show what they did at work. However, it did transpire that the applicants expected to pass, on account of their perceptions of their considerable experience gained. The onus is on the applicants to demonstrate that they have mastered the learning outcomes of the subject, based on what they have done and learnt in the past. 


\section{Questionnaire}

Another research instrument was the questionnaire, which asked the respondents about the RPL process and RPL assessment methods. It transpired that the oral interview and PoE were the assessment methods that they would have preferred to be assessed with. The RPL assessors were in agreement, although the traditional assessment method of a written examination is still utilised, as it adheres to the RPL principles of validity, reliability, and authenticity.

The applicants were questioned on how they experienced the three assessment methods used to assess them. In their answers on the written exam as assessment method, it was clear that they did not struggle to interpret the questions, even if some were poorly answered. They conceded that the questions tested the knowledge and skills they had acquired in industry - an important finding, as the aim of the assessment methods was two-fold: to test their mastery of the learning outcomes, as well as their prior learning.

Similarly, the applicants indicated that the oral interview questions tested the knowledge and skills they had acquired in industry. They showed a preference for the oral interview assessment, and felt comfortable in answering the questions.

With regard to the PoE, it appeared they experienced challenges in the compilation of the portfolio.

The open-ended questions in the questionnaire revealed the opinions of the applicants on the fairness of the assessments, as well as the RPL process as a whole. The applicants felt that the assessment methods used to assess them were fair and reliable. As for the RPL process, they required some orientation (from the assessors) before the RPL process, since they had no idea what to expect from the assessment methods.

Furthermore, they commented on the length of the whole RPL process, which caused them stress. The length of time that the RPL process takes has been identified as an obstacle to the applicants. This can be attributed to the number of academic committees that have to verify, and approve, the applications. A contributing factor is that the University Senate only convenes three times-a-year.

The fact that there was no feedback during the RPL process caused further anxiety. They would like to track the progress of their applications. A suggestion was made to have the information available online.

\section{Focus group interview}

The third research method was a focus group interview (of eight RPL applicants). They were 
questioned on their expectations, prior to the assessments. It became apparent that they expected to be given materials to study. In addition, they did not expect to be tested in the same academic way as regular students: 'And it was also a shock I mean for me after so many years to write a formal exam. That was really, it wasn't a good experience' (40 years old, White female, no. 1); 'they must not do the study what they do in the day with the students, we are not the same as the student.' (43 years old, Black male, no. 3).

In terms of the fairness of the assessments, the applicants thought the methods were fair, and relevant to the knowledge and skills they had obtained at work. However, they did question the theoretical nature of the questions: 'See but that's the thing, then it comes back to the theory which we didn’t know or get to study' (45 years old White female, no. 2).

Some of the applicants mentioned that they thought they had to study beforehand, while another said that one should not prepare for RPL, as it was supposed to test one's knowledge of a certain subject in one's environment. Another applicant suggested that the paper be generic.

The RPL applicants were positive about the PoE, as an assessment method. They were in agreement that it tested them in their environments. They were concerned, though, that, because of the different working environments, they might be disadvantaged, if they did not present the examples in the way that the learning outcomes of the subject dictated.

When asked about their experience of the oral interview, the responses were positive. Answers ranged from applicants feeling nervous, to applicants feeling relaxed, because the interviewers were accommodating.

There were some challenges mentioned by the RPL applicants, with reference to the RPL process: although they felt accommodated by the assessors, they would like to receive continual feedback while the process was on-going. Furthermore, they would like clear step-by-step guidelines on the process:

I think overall for the RPL we didn't get the proper information, the proper orientation, as to what is the step, what is expected who must we go to ask that, because when you are busy dealing with the individual it's more, what can I say, it's more private, you don't know what is happening until you express yourself, you have to phone the guy and ask him are they going to give me the marks, how much, did I pass? How far is it going as they're saying, so at least when you're applying for RPL they must sit with you and tell you what is affected. It is very very very serious, it's very private and you experience it like the hard way and you expecting it at the moment so I think we must have a proper knowledge as to how it works.

(42 years old, Black female, no. 10)

One applicant was critical of the RPL office, stating that she was frustrated, as it seemed to her that 'the goal posts shifted continually'. Another barrier was the length of the RPL process: 
I would just say the process is taking too long. For RPL, I don't see the need for after you've written and your lecturer assessed us ... why must it go through all these academic departments and approval, do they really look at it or is it just like a process? I would just like to get feedback more quicker. I mean that's the only thing I can say with the RPL it's just a very very long process. (47 years old, White female, no. 3)

The primary concern was that, by the time they found out whether they had passed (or not), the year was almost over, and, should they have failed, they would have to wait until the following year to re-enrol for the subject at the University. The latter might prove problematic, because this is a residential university, not a distance one; hence, the applicants would not be able to attend class, unless permission was granted by their supervisors - which seemed unlikely. Furthermore, if they failed to pass the RPL assessments, they are not allowed to re-apply until a reasonable period of time may have elapsed. The rule-of-thumb at the University currently is three years, but there are no official guidelines; therefore, an applicant may apply again sooner, but has to prove that additional learning has taken place in the meantime. Currently, the length of the process is what it is - one is bound by the dates on which all the committees sit. The University Senate convenes three times-a-year; hence, the assessors and applicants have to plan very carefully around these dates.

The applicants preferred an oral assessment, and a portfolio of evidence. In addition, they would like to include reference letters from their supervisors in the PoE.

\section{Assessor interviews}

Three RPL assessors were questioned in semi-structured interviews. These assessors shared the view of the applicants that the RPL process was a barrier. Two assessors also mentioned that the academic nature of the assessments (i.e., being in an academic environment, and writing an academic paper) could be seen as an obstacle to applicants.

Two assessors preferred all three methods currently used, as assessment methods, while one assessor (65 years old White female Assessor, no. 1) was not in favour of the PoE, as she felt that the documents included were seldom the work of the applicant, i.e., she questioned the authenticity of the documents:

... but there is the matter of ethical considerations with the portfolio specifically, and the assessment methods I feel should be left to more than one person. I think there should be a second examiner or an interview should not be conducted one-on-one. So that the validity is ... is unquestionable.

On interrogating the assessors on RPL principles of assessment, they believed the current assessment methods adhered to the RPL principles of validity and reliability. Validity is 
maintained, because the learning outcomes are tested. The methods are reliable, as there are always two assessors during the assessments. In terms of authenticity, the PoE was the only assessment method that could lack authenticity, if the applicants did not include their own documents; however, this could be resolved during an oral interview, whereby the applicant is questioned on the contents of the PoE.

The assessors agreed that there should be some form of training given to applicants, before they compiled a portfolio, but it needed not be formal. Informal consultations with applicants before the commencement of the assessments would prove valuable as well.

Two assessors felt that an applicant's language proficiency, and their performance in the assessment, could not be separated, although one assessor was of the opinion that, since the applicants usually worked in an environment where English was the lingua franca, it should not impact that much on their performances. Although the assessors did not feel that the assessments might be too academic in nature, they conceded that the applicants might view them in that way.

\section{CONCLUSIONS AND RECOMMENDATIONS}

RPL assessments should be based on the RPL principles of validity, reliability, fairness, authenticity, and appropriateness. The assessment methods currently employed are valid, since the learning outcomes of the subject, 'English Business Communication', are tested; applicants' prior learning is taken into consideration, as a situation similar to their work environment/the course that they apply for, is used as a basis for the written exam, and oral assessments. Applicants are encouraged to use examples from their work environments, when answering the questions. The assessments are reliable, as two assessors are involved in the execution of the assessments. The written and oral assessment methods are seen as reliable and authentic, as the applicant is physically present, as well as two RPL assessors, who are subject specialists. In terms of the PoE, validity, as well as authenticity, could be verified with an oral interview. Authenticity could be further enhanced by the inclusion of a reference letter by the applicant's line manager.

Whilst some applicants interrogated the fairness of the assessments (especially the 'theoretical' written exam), the majority did regard the assessments as fair, as they tested the knowledge and skills acquired in industry.

The literature suggests that assessment methods should be fit-for-purpose, thus safeguarding the appropriateness principle. The assessment methods chosen, thus far, were appropriate, as this particular RPL assessment relates to RPL for credit, or advanced standing. 
It refers to one subject, and in order to test whether RPL applicants have mastered the learning outcomes sufficiently, the three methods of written exam, oral interview, and PoE, were appropriate assessment methods.

All three assessment methods employed, since 2010, for the subject, 'English Business Communication', are suitable RPL assessment methods for subject RPL. The question is whether one is more suitable than the other. In terms of the efficient use of time, the written exam and oral interview might be more appropriate, as both these assessments could be scheduled on the same day, thus optimising time spent by assessors and applicants. The applicants, though, preferred the combination of PoE and oral interview, as assessment methods. As the RPL assessors pointed out, these three methods serve different purposes. It might be possible to employ all three assessments, especially if there is a gap in the PoE, in terms of learning outcomes not addressed. An example would be an investigative report - one of the learning outcomes of the subject. The applicant would either have to conduct a short investigation at their workplace, to show that they had the skills, or it could be tested with a written exam.

Some applicants felt that they had to study for the assessments, whereas RPL is about matching your prior learning with the learning outcomes of a subject. The challenge is how to assess the outcomes that the applicant does not deal with on a daily basis, since the applicant will receive credits towards an academic qualification; therefore, they must show that they have mastered the learning outcomes, the same as a conventional student.

Obstacles encountered by the assessors were: policy and guidelines; applicants' unwillingness to do a written academic test; and, logistical issues, regarding the process.

The applicants raised three major concerns, regarding the RPL process: firstly, they required orientation before the whole RPL process started - one of the applicants suggesting a step-by-step guide of the whole process. While there is an official document, citing the RPL process employed at the University - this document shows the path from applying for RPL until Senate ratification, it contains no guidelines about assessment procedures and methods.

Applicants also wanted to know exactly how they would be assessed, as this obviously caused them some anxiety.

They were of the opinion that the whole RPL process took too long, and required feedback, either from the RPL officer, or the academic department, on where, in the process, their application was. They were also not made aware, at the time of applying, how long the process would take.

Assessors should discuss the three different assessment methods with the applicants. They 
should be given guidelines on what each assessment entails, e.g., written exam (guidelines on academic writing); oral interview (guidelines on what to expect at the oral interview); portfolio of evidence (guidelines on how to prepare a PoE).

The applicants should be given an opportunity to voice their concerns, and ask questions, regarding the assessments. It might be prudent to choose two assessment methods, in consultation with the applicants. However, the oral interview should be one of the assessments, because it offers the assessors an opportunity to test the authenticity of the portfolio, as well as to assess the applicant's oral communication skills.

With regard to the RPL process, it is suggested that the following be considered:

- $\quad$ Conduct a preliminary interview with the applicants, whereby any clarifications, regarding the applicant's experience, can be given, the assessment methods discussed, the process explained, and questions answered.

- $\quad$ Liaise more efficiently with the officers at the RPL office. There should be clear guidelines from the University on the responsibilities of the RPL office, and those of academic departments.

- Give clear instructions on who should be responsible for feedback to applicants after the assessments are completed.

- A document, booklet, or toolkit, should be developed by the assessors in the academic department, stipulating the whole RPL process clearly from the application at the RPL office until Senate ratification. This toolkit should contain:

i) The RPL policy and process of the University;

ii) An indication of what the applicant should bring to the preliminary interview;

iii) Space for assessment dates;

iv) Guidelines on the three assessment methods, as well as a time-frame for the implementation of each method;

v) An indication of dates through the year when the relevant departmental and other committee and Senate meetings will take place - the assessor and applicant can then roughly predict how long the process will take from the time of assessment;

vi) Contact details of the assessors; and,

vii) A page, whereon the applicants declare that they understood, and were satisfied with the process.

Finally, further research could be conducted in the area of RPL for advanced standing, 
specifically in language subjects (e.g., the correlation between the applicants' language proficiency and their performances in RPL for advance standing) - this is especially appropriate in the current context of higher education, wherein the language of instruction is English in the majority of universities in South Africa. Those who do not have English as a language of instruction are gradually pressured to do so. Equally interesting would be academics' attitudes toward RPL at university.

\section{NOTE}

1 This article is based on a doctoral study (Rossouw 2015).

\section{REFERENCES}

Andersson, P., and A. Fejes. 2010. Mobility of knowledge as a recognition challenge: Experiences from Sweden. International Journal of Lifelong Education 29(2): 201-218. http://dx.doi.org/ 10.1080/02601371003616624 (accessed 28 February 2012).

Armsby, P. 2013. Developing professional learning and identity through the recognition of experiential learning at doctoral level. International Journal of Lifelong Education 32(4): 412-429. http://dx.doi.org/10.1080/02601370.2013.778070 (accessed 1 October 2013).

Aspin, D. N., and J. D. Chapman. 2000. Lifelong learning: concepts and conceptions. International Journal of Lifelong Education 19(1): 2-19. http://dx.doi.org/10.1080/026013700293421 (accessed 1 October 2013).

Beekman, L. 2001. Recognition of prior learning: an educational correction. Progressio 23(2). http://uir.unisa.ac.za/handle/10500/5110 (accessed 21 February 2012).

Billett, S. 2010. The perils of confusing lifelong learning with lifelong education. International Journal of Lifelong Education 29(4): 401-413. http://dx.doi.org/10.1080/02601370.2010.488803 (accessed 28 February 2012).

Breier, M. 2011. South Africa: Research reflecting critically on Recognition of Prior Learning (RPL) research and practice. In Researching the Recognition of Prior Learning: International Perspectives, ed. J. Harris, M. Breier and C. Wihak. Leicester: NIACE.

Cretchley, G., and J. Castle. 2010. RPL and adult education: good bedfellows in higher education in South Africa? International Journal of Lifelong Education 20(6): 487-501. http://dx.doi.org/ 10.1080/02601370110088463 (accessed 18 June 2015).

Department of Higher Education. 2013. Ministerial task team on a national strategy for the recognition of prior learning (RPL). Final report incorporating a proposal for the national implementation strategy. January 2013. www.dhet.gov.za/ResearchNew/37. Recognition of prior learning.pdf (accessed 1 October 2013).

Dewey, J. 1916. Democracy and education: An introduction to the Philosophy of Education. New York: Macmillan Press.

DHET see Department of Higher Education.

Diedrich, A. 2013. Translating validation of prior learning in practice, International Journal of Lifelong Education 32(4): 548-570. http://dx.doi.org/10.1080/02601370.2013.778078 (accessed 1 October 2013).

Ellingson, L. 2009. Engaging crystallization in qualitative research. Thousand Oaks: SAGE Publications, Inc.

Frick, B. L. 2007. Integrating scholarship and continuing professional development (CPD) in the natural 
sciences at a South African University. PhD thesis. University of Stellenbosch, Stellenbosch.

Gibbons, M., C. Limoges, H. Nowotny, S. Schwartzman, P. Scott and M. Trow. 1994. The new production of knowledge: The dynamics of science and research in contemporary societies. London: Sage.

Harris, J. 1997. The Recognition of Prior Learning (RPL) in South Africa. Drifts and shifts in international practices. Cape Town: University of Cape Town.

Harris, J. 2000. Power, pedagogy and principles. Pretoria: Human Sciences Research Council.

Harris, J., M. Breier, M. and C. Wihak, eds. 2011. Researching the Recognition of Prior Learning: International perspectives. Leicester: Niace.

Hendricks, N. and T. Volbrecht. 2003. RPL as cognitive praxis in linking higher education, the African Renaissance and lifelong learning. South African Journal of Higher Education 17(1): 47-53.

Heyns, J. P. 2004. Recognition of Prior Learning (RPL): In search of a valid and sustainable mechanism for South Africa. MEd. dissertation. University of Pretoria, Pretoria.

Kirby, J. R., C. Knapper, P. Lamon and W. J. Egnatoff. 2010. Development of a scale to measure lifelong learning. International Journal of Lifelong Education 29(3): 291-302. http://dx.doi.org/ 10.1080/02601371003700584 (accessed 1 October 2013).

Knowles, M. S. 1970. The modern practice of adult education, from pedagogy to andragogy. http://www.clickpdf.com/download/0Oalu0/andragogy.pdf. (accessed 8 March 2012).

Kolb, D. 1984. Experiential learning: Experience as the source of learning and development. Englewood Cliffs: Prentice-Hall.

Michelson, E. 2012. A meditation on cross-dressing and prior learning assessment. PLAIO 1(1) http://www.plaio.org (accessed 10 March 2013).

Moore, A. and L. van Rooyen. 2002. Recognition of Prior Learning as an integral component of competence-based assessment in South Africa. South African Journal of Education 22(4): 293296.

Osman, R. 2004. Access, equity and justice: Three perspectives on recognition of prior learning (RPL) in higher education. Perspectives in Education 22(4): 139-145.

Pitman, T. and L. Vidovich. 2013. Converting RPL into academic capital: Lessons from Australian universities. International Journal of Lifelong Education 32(4): 501-517. http://dx.doi.org/ 10.1080/02601370.2013.778075 (accessed 1 October 2013).

Ralphs, A. 2012. Exploring RPL: Assessment device and/or specialized pedagogical practice? Journal of Education 53: 75-91.

Rossouw, S. 2015. Assessing Prior Learning in English Business Communication at a University of Technology: Policy, principles, methods, and procedures. (Unpublished doctoral thesis). Tshwane University of Technology, Pretoria.

Sandberg, F. and P. Andersson. 2011. RPL for accreditation in higher education - as a process of mutual understanding or merely lifeworld colonisation? Assessment and Evaluation in Higher Education 36(7): 767-780. http://dx.doi.org/10.1080/02602938.2010.488793 (accessed 19 October 2013).

Sweygers, A., K. Soetewey, W. Meeus, E. Struyf and B. Pieters. 2009. Portfolios for prior learning assessment: caught between diversity and standardization. The Journal of Continuing Higher Education, 57: 2, 92-103. http://dx.doi.org/10.1080/07377360902978194 (accessed 1 October 2013).

Van Kleef, J. 2007. Strengthening PLAR: integrating theory and practice in post-secondary education. Journal of Applied Research on Learning 1(2). http://www.uk.ecorys.com/ europeanInventory/publications/concept/plar.pdf (accessed 8 March 2012).

Van Rooy, T. 2002. Recognition of prior learning (RPL): From principle to practice in higher education. South African Journal of Higher Education 16(2): 75-82. 